\title{
A simulation model of the cost of the incidence of IDDM in Spain
}

\author{
W. M.H art ${ }^{1}$, C. E spinosa ${ }^{2}$, J . R ovira ${ }^{1}$ \\ ${ }^{1}$ SOIKOS, Barcelona, Spain \\ ${ }^{2}$ QF BAYER, Barcelona, Spain
}

Summary This study estimates the direct health care costs of the incidence of insulin-dependent diabetes mellitus (IDDM) in Spain. A discrete event simulation model was developed to approximate the natural history of a cohort of newly diagnosed patients in a given year and used to calculate the average costs which would accumulate during the lifetime of the group of patients. The model takes into account both the underlying costs of control and maintenance of the disease plus the additional costs of long-term complications that are likely to develop as the disease progresses. The model is based on national and international epidemiological and demographic information combined with local cost data. The number of newly diagnosed cases of IDDM each year, based on Spanish epidemiological data, was calculated to be approximately 1791 cases in 1994 . The baseline results from the model indicate that the average life expectancy of an IDDM patient is approximately 59.6 years with an average lifetime cost of 12.7 million pesetas per individual (1994 undiscounted values), 5.1 million pesetas per individual when discounted at a rate of $6 \%$ and 8060 million pesetas for the entire newly diagnosed cohort discounted at a rate of $6 \%$. Sensitivity analysis was undertaken in order to observe the effect on the result of changes in the values of key variables. [Diabetologia (1997) 40: 311-318]

Keywords Cost, incidence, insulin-dependent diabetes mellitus, model, simulation, Spain.
Insulin-dependent diabetes mellitus (IDDM) is considered to be one of the most important chronic diseases. The long-term consequences are substantial, affecting the welfare of society as a whole by drawing upon scarce medical resources as well as affecting the individual's health status [1]. Thus, IDDM is of major importance in health care planning as it affects health primarily through its chronic multisystem complications, rather than by acute metabolic crises related to

Received: 17 May 1996 and in revised form: 19 November 1996

Corresponding author: W. M. Hart, SOIKOS, Centre d'Estudis en Economia de la Salut i de Politica Social SL, Sardenya 229-237, 6-4 08013 Barcelona, Spain

A bbreviations: IDDM, Insulin-dependent diabetes mellitus; PVD, peripheral vascular disease; AMI, acute myocardial infarction; MAU, microalbuminuria; SMAU, significant microalbuminuria; PROT, proteinuria; ESRD, end-stage renal disease; TRAS, kidney transplant; RUN, initiation of simulation. insulin deficiency [2]. These chronic conditions include diabetic retinopathy $[3,4]$, coronary artery disease [4-6], nephropathy [7], neuropathy [8], cerebrovascular disease [8-10], and peripheral vascular disease (PVD) [11-12]. Treating IDDM therefore requires a variety of health care resources including hospital physician and general practitioner time.

Current interest in the epidemiological and health care aspects of IDDM in Spain is considerable [13] and in order to address the problem of estimating the lifetime direct health care costs of the disease, a study of the cost of the incidence of IDDM in Spain was planned. This study provides an estimate of the direct lifetime costs from the institutional perspective of an IDDM patient.

Despite the complexity of the task and although the epidemiological data are incomplete it is possible to carry out simulations using a mathematical model to assess the cost of the disease for a defined set of 
assumptions. This is the approach used in the current study as a first attempt to estimate the direct lifetime costs of IDDM in Spain, offering the flexibility to improve the results as further information becomes available.

\section{Materials and methods}

The cost of illness framework. It has been argued that estimates of the economic burden of a disease are useful for various reasons [14]. Apart from demonstrating the importance of a disease to society they can also help determine priorities for future research [15]. There are two approaches used when calculating the cost of a specific disease. By far the most common approach is the prevalence methodology in which costs are calculated for a given year. Although there are a number of prevalence studies of the cost of diabetes [1,16-19], their value is limited given that they cannot be used to determine priorities, as priorities are likely to be dependent on the long-term consequences of treatment interventions. An alternative approach, adopted in this study, follows an individual or group of individuals from diagnosis throughout their lifetime and would permit the evaluation of the effect of alternative treatment strategies or the introduction of, for example, new medical technologies.

The perspective also varies from study to study. Here, direct costs at the institutional level are considered.

Epidemiology of IDDM in Spain. The total amount of health care resources spent on treating and caring for diabetic patients will be related to the prevalence and incidence of the disease itself; hence, epidemiology is an ideal instrument for establishing the dimension of the problem of diabetes and its complications [20]. In this regard the St. Vincent Declaration underlined the need and urgency for updating epidemiological knowledge in each European country in order to establish treatment and prevention strategies for diabetes and its complications [21]. Until recently there was no information on the incidence of IDDM in Spain. In the past decade a number of consensus meetings have been held with the aim of initiating epidemiological investigations with a standardised methodology [22, 23].

The first data published using such a standardised methodology were obtained on the incidence of IDDM in Madrid [24]. The study included all those under the age of 15 from an at-risk population of 1105243 inhabitants retrospectively during the period 1985-1988. The estimated incidence was 11.3/ 100000 inhabitants/year. Similarly, in 1986, a programme was initiated in Catalonia [25] to accurately document the incidence data of IDDM for individuals under the age of 30 years during a 4-year period (at-risk population, 0-29 years; 2690394 inhabitants). The observed age-specific rates (per 100000 person years) were the following: $4.4(0-4)$; 9.9 (5-9); 17.5 (10-14); 11.4 (15-19); 11.3 (20-24) and 8.5 (25-29 years). The observed incidence by Goday et al. [25] in the $0-14$ age group was very similar to that found by Serrano-Ríos et al. [24]. The analysis was based on the results of the Catalan study given the wider age range considered and the similarity of results between the two studies in the more restricted range of 0-14 years. Using 1994 population estimates [26], a percentage distribution of new cases by age was calculated (Fig.1).

M anagement of ID D M in Spain: resource utilisation and costs. After consultation with a number of experts, and the most recent national and European consultative documents [27, 28],

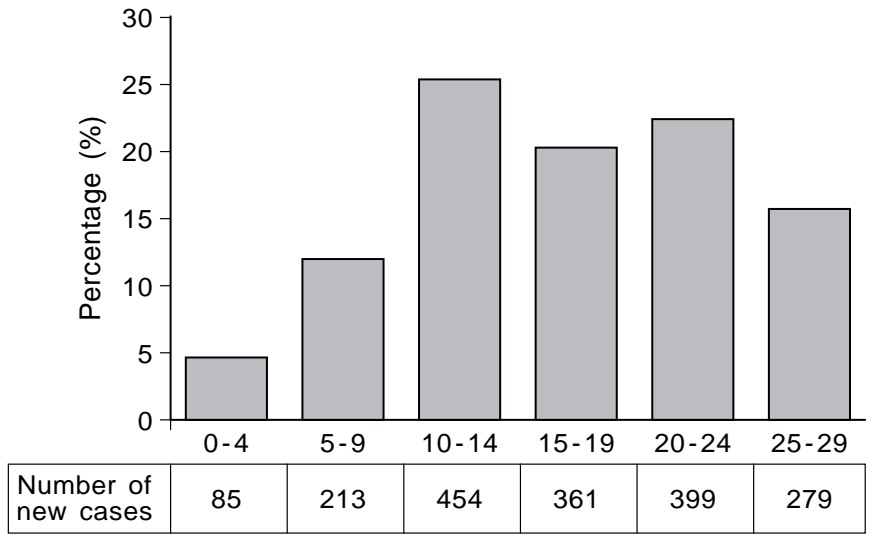

Fig. 1. Distribution of new cases of IDDM (years) in Spain in 1994

a consensus, based on a combination of actual practice and the medical attendance schedules described in the aforementioned documents, was estimated concerning the additional resources used in the management and control of IDDM. Costs were obtained from published articles, annual hospital reports, tariffs and unpublished research. Due to the additional costs associated with diagnosis in the first year, costs were calculated separately for the first year of diagnosis followed by annual costs for all subsequent years (without the costs of chronic complications). For a typical patient, first-year costs were assumed to consist of 7 days of hospitalisation including the initiation of insulin therapy and possible acute complications, outpatient visits, self-control, tests, insulin therapy and equipment (Table 1). Costs in subsequent years include similar resources but a reduction in the utilisation of inpatient hospitalisation (Table 2). One should bear in mind that the figures have been considered as an estimated average cost since it is unrealistic to assume that everyone with maintain the same medical attendance schedule.

Chronic complications and epidemiology associated with IDDM. As the disease progresses, additional resource needs will be added to the described underlying control and maintenance requirements which will remain fairly constant during the life of the patient. Additional resources and hence costs will appear due to the development of chronic complications. Although there are many complications related to IDDM this study was limited to an analysis of those which are assumed to have the greatest economic impact: nephropathy, retinopathy and cardiovascular complications, based on our conversations with clinical experts. As in a number of previous prevalence studies [29-31] and some cost-effectiveness evaluations of the screening and early treatment of nephropathy in IDDM patients [32] the study considers the typical progression of nephropathy among IDDM patients from the onset of microalbuminuria to the onset of renal failure with the need for dialysis or kidney transplant. The various stages considered with percentages, medians and ranges (in years) included in the model are the following [31]: IDDM onset to microalbuminuria (MAU) $(60 \% ; 12$ [3-25]); microalbuminuria to significant microalbuminuria (SMAU) $(75 \%$; 4 [28]); significant microalbuminuria to proteinuria (PROT) $(75 \% ; 4[2-8])$; proteinuria to end stage renal disease (ESRD) $(50 \% ; 10[3-18])$ and ESRD to dialysis $(100 \%$; no delay). In the case of dialysis to kidney transplant; kidney transplant to transplant failure and transplant failure to dialysis yearly data derived from national and international sources were used. 
Table 1. Estimated average costs (pesetas) per patient in the year of diagnosis

\begin{tabular}{lclc}
\hline Resource & Units $^{\mathrm{a}}$ & $\begin{array}{l}\text { Cost } \\
\text { (pesetas)/unit }\end{array}$ & $\begin{array}{l}\text { Cost } \\
\text { (pesetas) }\end{array}$ \\
\hline $\begin{array}{l}\text { Hospitalisation } \\
\begin{array}{l}\text { Visits } \\
\text { Specialist }\end{array}\end{array}$ & 7 days & $44042(29-31)$ & 308294 \\
$\begin{array}{l}\text { Nurse } \\
\text { Self-control }\end{array}$ & 4 & $9091^{\mathrm{b}}$ & 36364 \\
$\begin{array}{l}\text { Strips } \\
\text { Tests }\end{array}$ & 8 & $3312^{\mathrm{c}}$ & 26496 \\
$\begin{array}{l}\text { General analysis } \\
\begin{array}{l}\text { Insulin-average cost } \\
\text { (including syringes, needles, }\end{array}\end{array}$ & 552 & $70(32)$ & 38640 \\
$\begin{array}{l}\text { pen systems, etc. })^{\mathrm{d}} \\
\text { Reflectometer } \\
\text { Total (first year) }\end{array}$ & 5 & $1164(33)$ & 5820 \\
\hline
\end{tabular}

Data as described in text (ref. number)

${ }^{a}$ Resource utilisation according to the experts and consensus documents [27, 28];

b INSALUD annual report, Madrid 1993, updated to 1994;

c Contract programme of Bellvitge Hospital, Barcelona, updated to 1994;

d Based on a review of alternative administration systems;

e General catalogue. COFARES group (Madrid, Spain). October 1994;

f 133.94 pesetas $=1$ US $\$$ in 1994

Table 2. Estimated average annual costs (pesetas) per patient in years following year of diagnosis (without cost of chronic complications)

\begin{tabular}{|c|c|c|c|}
\hline Resource & Units $^{\mathrm{a}}$ & $\begin{array}{l}\text { Cost } \\
\text { (pesetas)/unit }\end{array}$ & $\begin{array}{l}\text { Cost } \\
\text { (pesetas) }^{\mathrm{e}}\end{array}$ \\
\hline Hospitalisation & 1.4 days & $44042(29-31)$ & 61659 \\
\hline Visits & 4 & $9091^{\mathrm{b}}$ & 36364 \\
\hline $\begin{array}{l}\text { Specialist } \\
\text { Self-control strips }\end{array}$ & 416 & $70(32)$ & 29120 \\
\hline Tests & 4 & $1164(33)$ & 4656 \\
\hline $\begin{array}{l}\text { General analysis } \\
\text { Average insulin cost } \\
\text { (including syringes, } \\
\text { needles, pen systems, etc.) }\end{array}$ & & & 65361 \\
\hline Reflectometer & 0.33 & $7500^{\mathrm{d}}$ & 2500 \\
\hline Total (following years) & & & 227164 \\
\hline
\end{tabular}

Data as described in text (ref. number)

${ }^{a}$ Resource utilisation according to the experts and consensus documents [27, 28];

b INSALUD annual report, Madrid 1993, updated to 1994;

c Based on a review of alternative administration systems;

d General catalogue. COFARES group. October 1994;

e 133.4 pesetas = 1 US \$ in 1994

Although morphologic lesions develop in the glomeruli of all diabetic patients after a few years of metabolic abnormality [33], many patients never have clinically important renal disease, even after many years of diabetes [34]. On the other hand, diabetic nephropathy with proteinuria, increased blood pressure, and a decline in renal function will develop in as many as $45 \%$ of IDDM patients [35]. The natural history of nephropathy is of particular relevance given the considerable cost of treating ESRD and that nephropathy is one of the principal causes of mortality in IDDM [36]. However, attempts to describe this natural history have been few [37]. Moreover, differences in methodological approach have precluded comparisons among studies [38] that could indicate environmental factors or improvements in the management of diabetes that have influenced the occurrence or progression of the disorder. Before 1987 no such study had ever been undertaken in Spain and although retrospective studies have now been performed such as the one by Esmatjes et al. [39] the limited results indicate a natural history similar to that of other countries and hence we have used more complete data from the international literature [40, 41].

Cardiovascular diseases have been divided into two groups: acute myocardial infarction (AMI) (Table 3) and peripheral vascular disease (PVD) (Table 4). Data for other categories of cardiovascular diseases were not considered to be of sufficient quality to be included in the study.

Information on the epidemiology of AMI was obtained from research undertaken by the Department of Endocrinology at Hospital de Cruces, Baracaldo [42, 43].

Costs and average survival data were obtained from recent Spanish publications such as a recent study by Lanchas et al. [44] who present an 8-year actuarial survival rate for diabetic patients (both types) after AMI of $55.9 \%$. On the assumption of constant mortality, an underlying condition of the 'DEALE' methodology [45], the estimated average life expectancy after such an event was calculated to be 13.8 years.

Other epidemiological data related to cardiovascular events were based on the aforementioned Spanish database $[42,43]$ and published studies in Spain combined with international data where no appropriate Spanish data were available. Amputation survival data was based on a worldwide review of the literature [46]: 1 year: $75 \%$; 2 years: $60 \%$; 3 years: $50 \%$; 4 years: $45 \%$ and 5 years: $33 \%$. Costs for peripheral bypass surgery and amputation were obtained from Spanish research [47].

In the case of retinopathy, an ocular examination is recommended to be performed annually 5 years after the initial diagnosis of IDDM [27]. From an economic perspective our main concern was the use of laser photocoagulation for which we have limited Spanish data provided by the research undertaken in Hospital de Cruces, Baracaldo: $0-5$ years after diagnosis: $0 \%$; $5-10$ years: $2,4 \% ; 11-20: 8.4 \%$ and more than 20 years: $53.6 \%$.

Cost of resources used in the treatment of diabetic complications. Costs were updated to 1994 values using the Spanish consumer price index since there is no specific index for medical technology inflation.

In the case of antihypertensive treatment we have taken the average cost per month of those medications generally given to diabetic patients from International Marketing Services [48]. The average cost per month was 2001 pesetas and hence the average cost per year was 24010 pesetas.

The annual cost of dialysis was based on a monthly cost of 280000 pesetas in 1993 [49] and subsequently updated to 1994 values.

Kidney transplant costs were obtained from a study undertaken by the investigation unit of the Ministry of Health [50] giving a value of 3502940 pesetas.

The cost of maintenance of kidney transplant patients has been based on standard cyclosporin treatment and was estimated to cost 1037512 pesetas in 1994 from the same Ministry of Health study [50].

Costs for AMI were based on diagnostic related group data from three Spanish hospitals [51-53]. The average cost of an AMI, with an average stay of 11 days, was 483141 pesetas. 
Table 3. Incidence of myocardial infarction

\begin{tabular}{lrr}
\hline Duration of disease (years) & No & Yes \\
\hline $0-4$ & 78 & 0 \\
$5-9$ & 129 & 78 \\
$10-19$ & 190 & 129 \\
$>20$ & 102 & 10 \\
Total & 499 & 217 \\
\hline
\end{tabular}

Number of new cases (YES) after a certain duration of the disease

Table 4. Incidence of peripheral vascular disease

\begin{tabular}{lcc}
\hline Duration of disease (years) & No & Yes \\
\hline $0-4$ & 76 & 2 \\
$5-9$ & 126 & 2 \\
$10-19$ & 188 & 2 \\
$>20$ & 100 & 12 \\
Total & 490 & 18
\end{tabular}

Number of new cases (YES) after a certain duration of the disease

For bypass and amputations, costs were based on an epidemiological and cost-effectiveness study of 526 patients undertaken by the Angiology and Vascular Surgery Service of Hospital La Paz, Madrid, during the period 1981 to 1990 [47].

For bypass surgery the costs are essentially those derived from the surgical intervention and the in-patient hospital stay with an average of 32.58 days and an average cost of 1061000 pesetas (updated to 1994).

Amputations can be divided into two categories: minor and major, with an average cost of 1740000 pesetas (updated to 1994). Values of 64800 pesetas and 1736 pesetas for photocoagulation and an ocular examination, respectively, were obtained from the College of Physicians, Barcelona [54] and unpublished research, respectively.

Simulation model. In this study a discrete event model was developed using SIGMA for windows simulation software (Schruben, Danvers, MA, USA) in which changes occur at particular instants in time. In a simulation of a discrete event model, time is advanced in discrete steps (variable and often random in length) to the next change of state. Hence a discrete event simulation skips over uninteresting time intervals rather than tracking detailed system dynamics. A description of the state of a discrete event model will necessarily include values for all its numerical attributes as well as any schedule it might have for the future. Changes in the state are called events. The basic model is illustrated in Figure 2, which illustrates the various states considered and their interrelationship. Each simulation cycle starts at the initiation of simulation (RUN) state based on the incidence of IDDM from the Catalonian study previously mentioned [25]. In combination with Spanish population data for the corresponding age groups that were defined in the incidence study, it was possible to construct a probability distribution of the time of onset of IDDM. By using this distribution, the event: time to onset, is selected randomly at which point the patient then enters the IDDM state, the diagnosis of IDDM, with a value varying between 0 and 29 years.

From IDDM there are two options: progression to the MAU state or eventual death based on standardised Spanish life expectancy data with no nephropathy complications. This process is repeated with the progression to SMAU or eventual death with an adjustment based on relative risk data for patients with MAU and no further nephropathy complications.

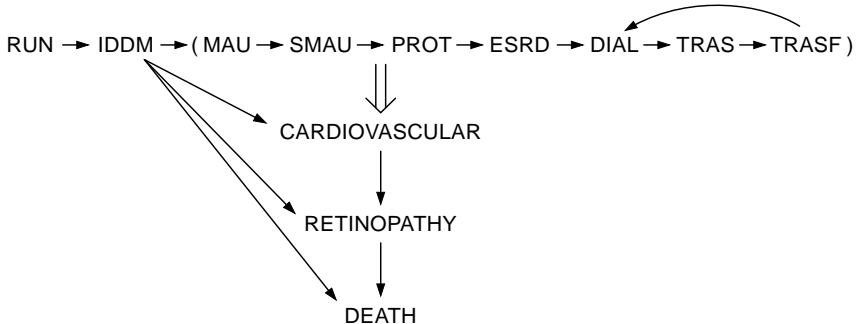

Fig. 2. Simplified representation of each simulation cycle. Run, initiation of simulation; IDDM, onset of IDDM; MAU, microalbuminuria; SMAU, significant microalbuminuria; PROT, proteinuria; ESRD, endstage renal disease; DIAL, dialysis; TRAS, renal transplant; TRASF, transplant failure

From SMAU to PROT and from PROT to ESRD a similar process occurs with an adjustment to life expectancy based on relative risk data and the time lags from the time to diagnosis to the time of onset of the different states.

At ESRD, it was assumed that haemodialysis would be undertaken immediately with the possibility of eventual death with no further nephropathy complications or kidney transplant (TRAS) based on data from the Catalonian Register of Renal Disease [55].

At TRAS, there are two possibilities: death or transplant failure, both being based on distributions from the international literature [41]. Until death or transplant failure the costs of transplant maintenance have also been included.

After transplant failure, it is assumed that the patient will be referred back to haemodialysis treatment until death (the possibility of a second transplant was not considered), the survival probability being based on that for kidney transplant with an adjustment for the time lag to transplant failure.

It was also necessary to include cardiovascular and retinopathy complications in the model although the modelling approach was somewhat different due to the format of the available data.

In the case of cardiovascular complications there is a clear impact on mortality and hence on overall costs. Data from the study undertaken by the Department of Endocrinology at Hospital de Cruces, Baracaldo [42, 43] were used. It was considered appropriate to combine data from the time intervals described in the study and calculate an overall time to complication for a proportion of all IDDM patients for each cardiovascular event. Costs and life-expectancy were based on the competing risk between nephropathy and cardiovascular complications.

If the duration after diabetes diagnosis and having possibly passed through the nephropathy section of the model was less than the average time to one of the cardiology events no adjustment was made.

On the other hand, when the simulated time to death after diagnosis was greater than the average time to cardiovascular event, an adjustment was made for a proportion of patients to the total life expectancy. This adjustment was based on the percentage of expected cardiovascular events. This process was repeated twice to take account of the data for AMI and PVD which led to bypass and then amputation. These adjustments have important implications for costs especially if they reduce or remove the need for expensive ESRD treatment due to a reduction in the total duration of the disease.

Finally, retinopathy which was not assumed to affect mortality independently was incorporated into the model. The main interest from an economic perspective was the proportion of patients requiring photocoagulation, for which the 
Hospital de Cruces study provided limited information. The proportion increases with the duration of the disease. It was also assumed that an eye examination would be undertaken once a year beginning 5 years after the initial diagnosis. An algorithm was therefore devised to take into account the increasing frequency of photocoagulation with increasing duration of the disease and an eye examination annually, apart from the initial 5 years of the disease.

Costs were calculated for each state in the model. For each cycle of the simulation the costs and duration in each state were summed to give a distribution of the total lifetime costs per patient as well as the total life expectancy per patient.

The model was run for a minimum of 2000 cycles which approximates the number of incident cases of IDDM per year in Spain (1791 based on the Catalonian incidence study [25] and was a large enough number to reach stable estimates of lifetime costs and life expectancy.

D iscount rate and sensitivity analysis. Two discount rates were considered in this analysis: $6 \%$ which is the rate currently proposed for economic evaluations in Spain [56] and $0 \%$ to illustrate the significant impact of discounting on long-term chronic diseases such as diabetes. As is normal in this type of analysis it is necessary to assess the impact of changes in key variables on the results given that some of the values of these variables are subject to varying degrees of uncertainty.

\section{Statistical analysis}

In this simulation we wanted to study the long-run, or steady state, behaviour of the system. To this end the run length was selected such that the point estimates of the lifetime costs and life expectancy converged to long-run averages with sufficiently small confidence intervals. In addition, initiation bias was reduced to a negligible level by deleting the first d observations of the total of $n$ observations were the run length $(n-d)$ was at least $10 \mathrm{~d}$.

\section{Results}

Figure 3 illustrates the relationship between total lifetime costs per patient. The average cost per patient was found to be 12.7 million pesetas. When discounted the average cost per patient was reduced to 5.1 million pesetas. This considerable reduction is to be expected due to the long-term duration of the disease. With a cohort of 1791 newly diagnosed IDDM patients per year a stream of health care costs amounting to 22746 million pesetas (9134 million pesetas when discounted) will be initiated each year.

The large variation observed in Figure 3 can be explained by the fact that only a minority of diabetic patients will require relatively expensive ESRD treatment leading to the higher total costs observed. In Table 5 a breakdown of costs is presented for the states defined in the model.

An elevated cost of maintenance due to the longterm nature of this component can be seen. The ESRD component is the next most important in

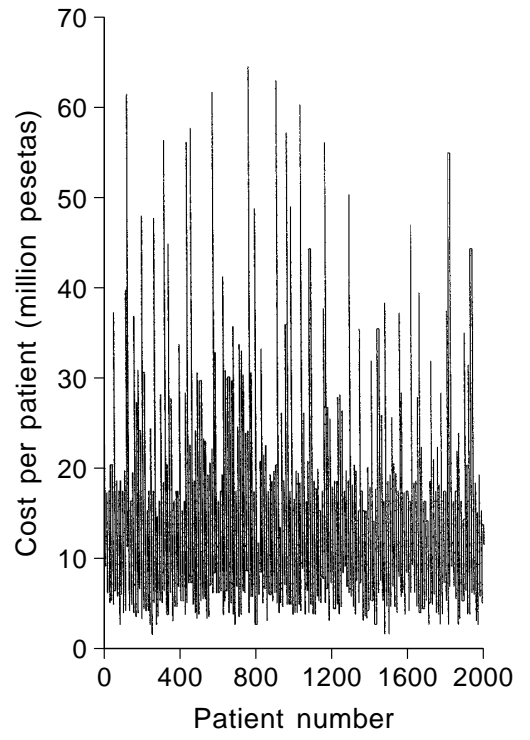

Fig. 3. Cost (million pesetas) per IDDM patient

Table 5. Average costs by condition (million pesetas)

\begin{tabular}{|c|c|c|c|c|c|c|c|c|}
\hline $\begin{array}{l}\text { Dis- } \\
\text { count } \\
\text { rate (\% }\end{array}$ & IDD & MAU & SMA & PRC & $\Gamma \mathrm{ESI}$ & $\mathrm{CA}$ & RET & TOT \\
\hline & & & & & & & & 12.7 \\
\hline & 2.95 & 0.41 & 0.20 & 0.53 & 0.89 & 0.09 & 0.03 & 5.1 \\
\hline
\end{tabular}

Cost by state in model

IDDM, Underlying cost of diagnosis and maintenance until complications;

MAU, cost of microalbuminuria;

SMAU, cost of significant microalbuminuria;

PROT, cost of proteinuria;

ESRD, cost of end stage renal disease;

CARD, cost of cardiovascular disease;

RET, cost of retinopathy;

TOT, total cost

terms of cost. The effect on disease states reached several years after the onset of diabetes is appreciable. In the base case approximately $15 \%$ of patients will eventually develop renal complications with an average cost of this component being 16.2 million pesetas (5.9 million pesetas with discounting). The low contribution of cardiovascular diseases to the overall costs can be explained by the low incidence of PVD events based on the Spanish database. If the proportion of patients who will eventually require ESRD treatment could be reduced, the average lifetime cost would also be expected to change. Similarly, if further treatment is administered at the early stages of diabetic nephropathy with a subsequent increase in the median time to manifestation of ESRD average costs would be expected to fall. Sensitivity analysis (Table 6) shows the effect of increasing the median duration in each state and increasing the yearly maintenance cost. The reduction in overall cost due to the prolongation in each nephropathy state is diminished 
Table 6. Summary of sensitivity analysis (discount rate $6 \%$ )

Estimated total cost (million pesetas)

Median duration in nephropathy states

Increased by $20 \%$

12.4

Cost of yearly maintenance

increased by $20 \%$

15.2

due to effect of discounting on events occurring many years into the future.

The average life expectancy for an IDDM patient was calculated to be 59.6 years. This figure was derived using a combination of Spanish and international life expectancy data and will obviously change as more Spanish data become available.

A review of the output data set reveals that only a minority of patients will eventually receive dialysis or transplant, a conclusion consistent with the transition probabilities from Seigel [38]. However, in those cases where ESRD is experienced costs may escalate to over 64 million pesetas (23.4 million pesetas with discounting) and in those cases where ESRD treatment is required the costs attributable to this chronic complication account for up to $85 \%$ of the total cost.

\section{Discussion}

In this study a discrete event simulation model has been developed in order to approximate the cost of the incidence of diabetes in Spain. The model permits both the calculation of total health care costs and total life expectancy for IDDM patients.

From the outset we kept in mind that due to the limited epidemiological data even the most sophisticated model could only be a rough approximation of reality, given the many possible combinations of diabetic complications and the difficulty of finding reliable estimates of both transition probabilities and costs. In fact, to our knowledge, almost all previous studies have used the prevalence method due to the difficulty of calculating costs from using the incidence approach. A recent study [57] has been published in which costs of an IDDM patient were considered over a span of 35 years; however, that study was based on a single imaginary patient who had contracted the disease at a particular young age.

It should be emphasised that questions about appropriate levels of expenditure cannot be answered by cost-of-illness studies on their own. Such studies only indicate the actual cost, not whether it is too low or too high. However, the incidence approach is much more appropriate if at a later stage one wishes to undertake an economic evaluation such as a costeffectiveness analysis in which the impact of different treatment modalities such as screening, more aggressive anti-hypertensive treatment or new medical technologies are compared with current treatment strategies. Such cost-effectiveness analyses may be facilitated by the model that has been developed and could be used as the basis for future economic evaluations, i.e. the prophylactic administration of anti-hypertensive medication to diabetic patients with MAU.

Changes in the natural history of IDDM complications such as the declining incidence of nephropathy [58] and the effect of optimum control of glycemia based on the Diabetes Control and Complications Trial (DCCT) [59] would suggest that the results will be modified as more epidemiological data become available. A recent study [60] indicated that efforts to reduce the frequency of diabetic nephropathy should concentrate on haemoglobin $\mathrm{A}_{1}$ values above $10.1 \%$. Stricter control of glycemia and haemoglobin may not only reduce the frequency of nephropathy complications and increase average life expectancy but may actually also save money.

In a study of this nature a number of assumptions must be made, and of course there are a number of limitations. Transition probabilities and epidemiological data, essential inputs for this type of modelling approach, have been derived largely from the international literature or preliminary Spanish research. This highlights both the need for better, more robust local epidemiological data and that the results be interpreted with caution.

Additionally, it should be noted that the cost reported in this study concentrates on what were perceived to be the principal economic drivers such as nephropathy and cardiovascular complications while excluding other illness episodes experienced by patients with IDDM, such as diabetic ketoacidosis, or soft tissue infections resulting from ulcers, trauma, and/or foreign bodies, etc. It does not represent a societal perspective because only direct costs are included. Indirect cost items such as loss of productivity due to chronic complications of ESRD, blindness, and early mortality among others, have similarly not been included. Finally, a model of this type needs to be evaluated [61] if possible with empirical data. This process of comparing the theoretical results with actual data may then lead to adjustments that improve the credibility of the model. However, given the nature of the problem, dealing with the lack of longterm historical information in itself presents problems.

Although the limitations cannot be overlooked we believe that the novel approach used in this study is more relevant than that of many previously published cost-of-illness studies that concentrate on the cost of a specific disease in a given year. The modelling approach that we have reported in this article could be applied, with adaptations, to other chronic diseases. 
A cknowledgements. The authors wish to thank Drs. A. Goday, R. Gomis, M. Mata, M. Trilla and J. A. Vézquez for their helpful suggestions in performing this study. The work was supported by Quimica Farmaceutica Bayer, Barcelona, Spain.

\section{References}

1. Gerard K, Donaldson C, Maynaud A (1989) The cost of diabetes. Diabet Med 6: 164-170

2. Piart J (1978) Diabetes mellitus and its degenerative complications: a prospective study of 4400 patients observed between 1947 and 1973. Diabetes Care 1: 168-188

3. Dwyer M, Melton J, Ballard D, Palumbo P, Trautmann J, Chu C (1985) Incidence of diabetic retinopathy and blindness: a population based study in Rochester, Minnesota. Diabetes Care 8: 316-322

4. Hiller R, Sperduti R, Podgor M, Ferris F, Wilson P (1988) Diabetic retinopathy and cardiovascular disease in type II diabetics: the Framingham heart study and the Framingham eye study. Am J Epidemiol 128: 402-410

5. Walter B, Palumbo P, Roberts W (1980) Status of the coronary arteries at necropsy in diabetes mellitus with onset after age 30 years: analysis of 229 diabetic patients with and without clinical evidence of coronary artery disease and comparison to 183 control subjects. Am J Med 69: 498-506

6. Freedman D, Gruchow H, Bamrah V, Anderson A, Barboriak J (1988) Diabetes mellitus and arteriographically documented coronary artery disease. J Clin Epidemiol 41: 659-668

7. Humphrey LL, Ballard DJ, Frohnert PP, Chu CP, O'Fallon WM, Palumbo PJ (1989) Chronic renal failure in noninsulin-dependent diabetes mellitus: a population-based study in Rochester, Minnesota. Ann Inter Med 111: 788-796

8. Palumbo P, Elveback L, Whisnant J (1978) Neurologic complications of diabetes mellitus: transient ischemic attack, stroke, and peripheral neuropathy. Adv Neurol 19: 593-601

9. Abbot R, Donahue P, MacMahon S (1987) Diabetes and the risk of stroke: the Honolulu Heart Program. JAMA 257: 949-952

10. Barrett-Connor E, Khaw K (1988) Diabetes mellitus: an independent risk factor for stroke? Am J Epidemiol 128: 116-123

11. Melton L, Macken K, Palumbo P, Elveback L (1980) Incidence and prevalence of clinical peripheral vascular disease in a population-based cohort of diabetic patients. Diabetes Care 3: 650-654

12. Zimmerman B, Palumbo P, O'Fallon W, Osmundson P, Kazmier F (1981) A prospective study of peripheral occlusive arterial disease in diabetes I, clinical characteristics of the subjects. Mayo Clin Proc 56: 217-222

13. Figuerola D, Castell D, Lloveras G (1988) La diabetes on España. Análisis de la prevalencia y atención médica según el consumo de fármacos y material de autocontrol. Medicina Clínica 91: 401-405

14. Drummond MF (1992) Cost-of-illness studies: a major headache? Pharmaco Economics 2: 1-4

15. Black DAK, Pole D (1975) Priorities for biomedical research: indices of burden. Br J Soc Prev Med 29: 222-227

16. Leese B (1992) The costs of diabetes and its complications. Soc Sci Med 35 (10): 1303-1310

17. Huse DM, Oster G, Killen AR, Lacey MJ, Colditz GA (1989) The economic costs of non-insulin dependent diabetes mellitus. JAMA 262: 2708-2713
18. Triomphe A (1991) The socio-economic costs of diabetic complications in France. Diabet Med 8 [Suppl]: s30-s32

19. American Diabetes Association (1992) Direct and indirect costs of diabetes in the United States in 1992. Espexs S. A. Publicaciones Médicas

20. Editorial (1989) Epidemiology of IDDM. Is it needed? Diabetes Care 12: 506-508

21. WHO, IDF (1990) The Saint Vincent Declaration. Giornale Italiano di Diabetologia 10 [Suppl]: 143

22. Recommendations from the International Workshop on the Epidemiology of IDDM (1985) Philadelphia Diabetes Care. 8 [Suppl1]: 5-9

23. Green A, King H, Laporte R (1986) Workshop on diabetes registers. The role of IDDM registers in diabetes research and care. In: Serrano-Rios M, Lefebvre P (eds) Diabetes 1985. Elsevier, Amsterdam, pp 247-252

24. Serrano-Ríos M, Moy C, Martín-Serrano R et al (1990) Incidence of type 1 (insulin-dependent) diabetes mellitus in subjects 0-14 years of age in the Comunidad de Madrid, Spain. Diabetologia 33: 422-424

25. Goday A, Castell C, Tresserras R, Canela R, Taberner J, Lloveras G, Catalan Epidemiology Diabetes Study Group (1992) Incidence of type 1 (insulin-dependent) diabetes mellitus in Catalonia (Spain). Diabetologia 35: 267-271

26. Boletín mensual de estadística. Agosto/Septiembre 1995. 44/45. Instituto Nacional de Estadística, Madrid

27. Subdirección General de prestaciones y evaluación de Tecnologías Sanitarias (1994) Tratamiento intensivo de la diabetes mellitus tipo I. Borrador cedido por el Presidente de la Sociedad Española de Diabetología

28. European IDDM Policy Group (1993) Consensus guidelines for the management of insulin-dependent (type I) diabetes. Medicom Europe BV

29. Jönsson B (1983) Diabetes-the cost of illness and the cost of control. Estimate for Sweden 1978. Acta Med Scand [Suppl] 671: 19-27

30. Nabarro J (1988) Diabetes in the United Kingdom. Some facts and figures. Diabet Med 5: 816-822

31. Siegel J, Krolewski A, Warram J, Weinstein M (1992) Costeffectiveness of screening and early treatment of nephropathy in patients with insulin-dependent diabetes mellitus. J Am Soc Nephrol 3: S111-S119

32. Narins B, Narins R (1988) Clinical features and healthcare costs of diabetic nephropathy. Diabetes Care 11 (10): 833

33. Osterby R (1983) Basement membrane morphology in diabetes mellitus. In: Ellenberg M, Rifkin H (eds) Diabetes mellitus: theory and practice. 3rd edn. Medical Examination Publishing New York, pp 323-341

34. Oakley W, Pyke D, Tattersall R, Watkins P (1974) Longterm diabetes: a clinical study of 92 patients after 40 years. Q J Med 43: 145-156

35. Andersen A, Christiansen J, Andersen J, Kreiner S, Deckert T (1983) Diabetic nephropathy in type 1 (insulin-dependent) diabetes: an epidemiological study. Diabetologia 25: 496-501

36. Knowles H (1974) Magnitude of the renal failure problem in diabetes. Kidney Int 6: 2-7

37. Krolewski A, Warram J, Christlieb A, Busick E, Kahn C (1985) The changing natural history of nephropathy in type 1 diabetes. Am J Med 78: 785-792

38. Kaplan M, Feinstein A (1973) A critique of methods in reported studies of long-term vascular complications in patients with diabetes mellitus. Diabetes 22: 160-174

39. Esmatges E, Gutiérrez A, Goday A et al (1988) Historia natural de la nefropatía en la diabetes mellitus tipo 1 . Med Clin (Barc) 90: 47-49 
40. Borch-Johnson K, Andersen P, Deckert T (1985) The effect of proteinuria on relative mortality in type 1 (insulin-dependent) diabetes mellitus. Diabetologia 28: 590-596

41. Najarian J, Kaufman D, Frud D, et al (1989) Long-term survival following kidney transplantation in 100 type 1 diabetic patients. Transplantation 47 (1): 106-113

42. Goicolea I, Mancha AI, Ugarte E, Vázquez JA (1995) Prevalence de la retinopatía diabética en una población de base hospitalaria. Relación con otras complicaciones diabéticas. Endocrinologiy 42 (9): 22-26

43. Goicolea I, Mancha AI, Latorre K, Vázquez JA (1995) Prevalencia de microalbuminuria y proteinuria en una población diabética hospitalaria, relación con las demás complicaciones diabéticas. Avances en Diabetología 10: 11-18

44. Hernández Lanchas C, Parilla Herranz P, Llorente Domingo O, Aparicio Martínez J, Arranz Nieto M, Durán Pérez-Navarro A (1990) Infarto de miocardio en pacientes con diabetes mellitus. Seguimiento a largo plazo. An Med Inter 7 (5): 248-251

45. Beck J, Kassirer J, Pauker S (1982) A convenient approximation of life expectancy (the "DEALE"). Am J Med 73: 883-897

46. De Frang R (1991) Basic data related to amputations. Annal Vasc Surg 5: 202-207

47. Reparaz L, Martínez I, Ligero J et al (1992) Epidemiología y análisis coste/efectividad de la angiopatía diabética en cirugía vascular. Angiología 6: 225-233

48. El mercado farmacéutico (1994) Pharmaceutical index. International Marketing Services, Madrid, Spain

49. Bestard Perrello JJ, Sevilla Pérez F, Corella Monzón I, Elola Somoza J (1993) La unidad ponderada asistencia (UPA): nueva herramienta para la presupuestación hospitalaria. Gaceta Sanitaria 7: 263-273
50. Análisis estructural y evaluación sanitaria del tratamiento de la insuficiencia renal crónica en España (1985) Ministerio de Sanidad y Consumo Ministry of Health, Madrid

51. Casas M (1991) Los grupos relacionados con el diagnóstico. Ed Masson, Barcelona

52. Complejo hospitalario A, Marcide-Novoa Santos (1993) Memoria General 1992. Badalona

53. Hospital Clínic i Provincial de Barcelona (1992) Memoria 1991, Barcelona

54. Collegi Oficial de Metges de Barcelona (1993) Nomenclator College of Physicians, Barcelona

55. Servei Catalá de la Salut (1993) Registre de Malalts de Catalunya. Informe estadístic 1992 Barcelona: Generalitat de Catalunya. Departament de Sanitat i Seguretat Social, pp 1-119 Dept. of Health and Social Security, Barcelona

56. Propuesta de estimación de algunos aspectos metodológicos de los análisis coste-efectividad y coste-utilidad en la evaluación de tecnologías y programas sanitarios. Badía X, Rovira J Evaluación económica de medicamentos. 1994 Luzán 5, S. A. de Ediciones

57. Stern Z, Levy R (1994) The direct costs of type I diabetes in Israel. Diabet Med 11: 528-533

58. Bojestig M, Arnquvist HJ, Hermansson G, Karlberg BE, Ludvigsson J (1994) Declining incidence of nephropathy in insulin-dependent diabetes mellitus. New Engl J Med 330: $15-18$

59. Witcher JW (1994) Implications of the DCCT. A pharmaceutical industry viewpoint and commentary. Diabetes Reviews 3: 272-278

60. Krolewski AS, Laffel LMB, Krolewski M, Quinn M, Warram JH (1995) Glycosated hemoglobin and the risk of microalbuminuria in patients with insulin-dependent diabetes mellitus. N Engl J Med 332: 1251-1255

61. Law AM, Kelton WD (1991) Simulation, modelling and analysis. McGraw-Hill Book Co, Singapore 